\title{
Partographic study of progress of labour in primigravida
}

\section{Sonal Bhuyar, Priyanka Deshmukh*}

Department of Obstetrics \& Gynecology, Dr. Panjabrao Deshmukh Medical College, Amravati, Maharashtra, India

Received: 16 December 2013

Accepted: 6 January 2014

\section{*Correspondence:}

Dr. Priyanka Deshmukh,

E-mail: drpriyanka1010@gmail.com

(C) 2014 Bhuyar S et al. This is an open-access article distributed under the terms of the Creative Commons Attribution Non-Commercial License, which permits unrestricted non-commercial use, distribution, and reproduction in any medium, provided the original work is properly cited.

\section{ABSTRACT}

Background: The objective of this study was to assess the value of partographic studies in the management of labour in primigravidae at term and to study the outcome of labour and mode of delivery.

Methods: Three hundred consecutive primigravid women were selected for this study according to the inclusion criteria at Dr. Panjabrao Deshmukh Memorial Medical College, Amravati (M.S.) during August 2009 - August 2011. 118 women who delivered before alert line served as control group, or group I, women who delivered after the alert line but before the action line; group II and group III; women who delivered after the action line. Maternal and neonatal outcomes were studied in each of three groups.

Results: Among the 300 women analysed, 118 (39.33\%) belonged to group I, 147 (47\%) to group II and 35 (11.67\%) belonged to group III. Mean duration of active phase of labour were $4.55 \mathrm{hrs}, 6.90 \mathrm{hrs}$ and $10.16 \mathrm{hrs}$ in group I, group II and group II respectively. Cervical dilatation in group I, group II \& group III was at the rate of $1.41 \mathrm{~cm} / \mathrm{hr}, 0.88$ $\mathrm{cm} / \mathrm{hr}$ and $0.59 \mathrm{~cm} / \mathrm{hr}$. respectively.

Conclusions: The number of LSCS, NICU, admissions and instrumental deliveries increased in group III, as compared to group I and II. Mean duration of active phase of labour increased as the partographic curve fell to the right of alert and action line.

Keywords: Partogram, Alert line, Action line, Labour

\section{INTRODUCTION}

There are not many areas of greater stress to the mother and the fetus than during labour, but it is only in recent years that a systemic and scientific attempt has been made to curtail the duration of labour. Obstetricians accepted labour as an event subjected to natural variations and largely outside medical control. There has now been a complete break in this tradition and the concept of passive supervision during labour in being replaced by one of active management.

Labour is a balance between the forces required to expel the fetus and the resistance of the cervices to dilate. Normal labour relies on these two forces being orchestrated physiologically.
The importance of the time element is reflected by the relationship of the fetal and maternal morbidity and mortality and the duration of labour, which after leads to surgical intervention with further danger to both the mother and the fetus. Management of such a patient presents a dilemma even for the experienced obstetrician. Hence prolonged labour must be prevented by timely and effective measures, so as to give the mother a safe and happy experience of labour and childbirth. The Cochrane data base review, 2009, has recommended the use of partogram curve in the developing countries because of poor access to health care resources. ${ }^{1}$

The partograph is a simple single page monitoring for the first stage of labour. As part of the Safe Motherhood initiative, launched in 1987, the World Health Organization have produced and promoted a partograph with a view to improve labour management and reducing 
maternal and fetal morbidity and mortality. The programme described that WHO - modified partogram is an excellent tool in reducing obstructed labour and its consequences.

The aim of this study was to analyse the spontaneous labour in primigravidae by means of a partogram and to study the outcome of labour and mode of delivery.

\section{METHODS}

A prospective observational study was conducted at the maternity unit in the department of Obstetrics and Gynecology, Dr. Panjabrao Deshmukh Memorial Medical College, Amravati. A total of 300 consecutive primigravid women with cephalic presentation in labour, who delivered between August 2009 to August 2011 were selected for this study, according to the inclusion criteria. Women with multiple pregnancies, medical disorders, malpresentation and preterm labour were exulted from the study.

The progress of labour was plotted on the WHO partogram, fetal and maternal parameters were noted on a proforma along with it. Partogram used in this study was simplified WHO partogram.

General protocol followed in our study was:

1) Plotting on partograph started at the time of admission in the labour room, on the extreme left of the graph and marked at zero time.

2) If admitted in active phase, plotting was done on the alert line.

3) Four hourly per vaginum examination was recommended.

4) Augmentation of labour was done by - amniotomy or oxytocin or both.

All patients were classified into three labour groups:

1) Women delivered before reaching alert line - Group I

2) Women delivered between alert and action line Group II

3) Women delivered after crossing the action line Group III

Statistical analysis was done using the statistical software graph pad Instat. Descriptive statistics; unpaired t test, Fisher's exact test and contingency table analysis were carried out. Statistical significance was set at a $\mathrm{P}$ value $<0.05$ with $95 \%$ confidence interval.

\section{RESULTS}

Out of the 300 primigravidae in labour, 118 (39.33\%) belonged to group I, $147(47.9 \%)$ belonged to group II and $35(11.67 \%)$ belonged to group III. Among them majority were in the age group of 20-25 years. i.e. 135 $(45 \%)$.
The percentage of cases with unfavourable Bishop score is $6.78 \%$ in group I, $7.48 \%$ in group II and highest i.e. $34.28 \%$ in group III. Whereas the average rate of cervical dilatation in active phase in various groups is; in group I $1.41 \mathrm{~cm} / \mathrm{hr}$, group II $0.88 \mathrm{~cm} / \mathrm{hr}$ and $0.59 \mathrm{~cm} / \mathrm{hr}$ in group III. The mean durations of active phase of labour in group I is $4.55 \mathrm{hrs}$, group II; $6.90 \mathrm{hrs}$ and $10.16 \mathrm{hrs}$ in group III, with a range of $2 \mathrm{hrs}$ to $11.45 \mathrm{hrs}$. The mean duration an active phase in group I i.e. $4.55 \mathrm{hrs}$ and group III i.e.; $11.45 \mathrm{hrs}$ is statistically significant ( $\mathrm{p}$ value $<0.001$ ).

\section{Table 1: Duration of active phase of labour in different groups.}

\begin{tabular}{|llll|}
\hline Group & N & Mean (hrs.) & Range (hrs.) \\
\hline Group I & 118 & 4.55 & $2-6.45$ \\
\hline Group II & 147 & 6.90 & $2-9.30$ \\
\hline Group III & 35 & 10.16 & $4-11.45$ \\
\hline Total & 300 & 7.20 & $2-11.45$ \\
\hline
\end{tabular}

In group I, mean duration of active phase of labour is $4.55 \mathrm{hrs}$. with cervical dilation at the rate of $1.41 \mathrm{~cm} / \mathrm{hr}$. In group II, it is 6.09 hrs. with cervical dilation at the rate of $0.88 \mathrm{~cm} / \mathrm{hr}$.

In group III, it is $10.16 \mathrm{hrs}$. with cervical dilation at the rate of $0.59 \mathrm{~cm} / \mathrm{hr}$.

In group I out of 118 women, 93 i.e. $78.81 \%$ had a spontaneous vaginal delivery, $21(17.80 \%)$ delivered by LSCS and 4 women i.e. $3.39 \%$ had instrumental delivery. In group II, $111(75.51 \%)$ delivered vaginally, 12 $(8.16 \%)$ had instrumental delivery and 24 (16.33\%) had LSCS. In group III $21(60 \%)$ delivery vaginally, 4 $(11.42 \%)$ by instrumental and $10(28.53 \%)$ had LSCS. Table 2 shows that there is statistically significant difference in the mode of delivery in group III compared to group I. (' $\mathrm{P}$ ' value $<0.001$ ). In our study the commonest indication for LSCS and instrumental delivery in group I was fetal distress $13(62 \%)$ in group II it was fetal distress $10(41.5 \%)$ and non-progressive labour $8(33 \%)$. In Group III non progressive of labour of $8(80 \%)$ was the major factor.

Table 2: Comparison of mode of delivery among all groups.

\begin{tabular}{|lllll|}
\hline \multirow{2}{*}{ Group } & \multicolumn{2}{l}{ Type of delivery } & Total \\
& Normal & LSCS & $\begin{array}{l}\text { Instrum } \\
\text { ental }\end{array}$ & T \\
\hline Group I & $\begin{array}{l}93 \\
(78.81 \%)\end{array}$ & $\begin{array}{l}21 \\
(17.80 \%)\end{array}$ & $\begin{array}{l}(3.39 \%) \\
118\end{array}$ \\
\hline Group II & $\begin{array}{l}111 \\
(75.51 \%)\end{array}$ & $\begin{array}{l}24 \\
(16.33 \%)\end{array}$ & $\begin{array}{l}12 \\
(8.16 \%)\end{array}$ & 147 \\
\hline Group III & $\begin{array}{l}21 \\
(60 \%)\end{array}$ & $\begin{array}{l}10 \\
(28.53 \%)\end{array}$ & $\begin{array}{l}4 \\
(11.42 \%)\end{array}$ & 3 \\
\hline Total & 225 & 55 & 20 & 300 \\
\hline
\end{tabular}

Mean birth weight in the present study group is 2608 grams, 2813 gms and 3002 gms. In group I, II and III respectively. 
In the present study the Apgar, score $\leq 5$ at $1 \mathrm{~min}$ is 5 (4.23\%), $10(6.80 \%)$ and $8(22.86 \%)$ in Group I, II and Group III respectively. The Apgar score $<7$ at 5 mins. Is seen in $2(1.70 \%), 3(2.04 \%)$ and $6(17.14 \%)$ in Group I, II and group III respectively. In the present study the NICU admission was more in group III compared to groups I and II $(\mathrm{P}<0.001)$.

Table 3: Comparison of NICU admission amongst groups.

\begin{tabular}{|llll|}
\hline Group & $\begin{array}{l}\text { Apgar } \leq \mathbf{5} \\
\text { at 1 min. }\end{array}$ & $\begin{array}{l}\text { Apgar }<7 \\
\text { at 5 min }\end{array}$ & $\begin{array}{l}\text { Apgar } \geq 7 \text { at } \\
\mathbf{1} \text { min }\end{array}$ \\
\hline Group I & $5(4.23 \%)$ & $2(1.70 \%)$ & $111(94.07 \%)$ \\
\hline Group II & $10(6.80 \%)$ & $3(2.04 \%)$ & $134(91.16 \%)$ \\
\hline Group III & $8(22.86 \%)$ & $6(17.14 \%)$ & $21(60 \%)$ \\
\hline Total & 23 & 11 & 266 \\
\hline
\end{tabular}

Table 4: Comparison of indication of instrumental delivery or LSCS amongst groups.

\begin{tabular}{|lllll|}
\hline \multirow{2}{*}{ Group } & $\begin{array}{l}\text { Type of } \\
\text { delivery }\end{array}$ & \multicolumn{3}{l|}{$\begin{array}{l}\text { Indication for ID } \\
\text { or LSCS }\end{array}$} \\
& FD & MSL & NPL \\
\hline \multirow{2}{*}{ Group I } & LSCS & 13 & 8 & - \\
\cline { 2 - 5 } & ID & 3 & - & - \\
\hline \multirow{2}{*}{ Group II } & LSCS & 10 & 6 & 8 \\
\cline { 2 - 5 } & ID & 12 & - & - \\
\hline \multirow{2}{*}{ Group III } & LSCS & 4 & - & 6 \\
\cline { 2 - 5 } & ID & 4 & - & - \\
\hline
\end{tabular}

ID instrumental delivery, FD fetal distress, MSL meconium stained liquor, NPL non progress of labour

Above table shows that fetal distress was the commonest indication in group I, while fetal distress and nonprogress of labour accounted for the most number of caesarean sections in the study group.

The average admission to delivery interval in group $\mathrm{I}$ is $7.53 \mathrm{hrs}$., in group II it is $12.82 \mathrm{hrs}$ and $17.13 \mathrm{hrs}$. in group III. Number of women undergoing more than 18 hour is maximum in group III i.e. $18(51 \%)$ as shown in Table 5.

Table 5: Admission to delivery interval in different groups.

\begin{tabular}{|lllll|}
\hline $\begin{array}{l}\text { Duration } \\
\text { in hrs. }\end{array}$ & Group I & Group II & Group III & Total \\
\hline$<10$ hrs. & 96 & 33 & 3 & 132 \\
\hline $10-18$ hrs. & 22 & 102 & 14 & 138 \\
\hline$>18$ hrs. & - & 12 & 18 & 30 \\
\hline Total & 118 & 147 & 35 & 300 \\
\hline
\end{tabular}

\section{DISCUSSION}

This study was undertaken to study the progress of labour in primigravid women with the use of a partogram. The use of alert line and the action line provided accurate and reliable guidelines for the obstetricians in managing labour. The operative delivery rate and perinatal morbidity rate were shown to be decreased as intervention was done as soon as the partograph showed abnormal labour pattern.

In the present study a total of 300 women were analysed by means of WHO simplified partograph and its effects on maternal and neonatal outcomes were measured as the curves fall more to the right side in the partogram.

Duration of the active phase of the labour is the main indicator of delayed progress of labour. The rate of cervical dilation was the main factor affected as the curve was shifted to right side, and these rates are comparable to those of the study conducted by Daftary and Mhatre. ${ }^{2}$ The mean duration of the second stage in our study is 5357 Min. In Zhang et al.'s study, ${ }^{3}$ the mean duration of the second stage of labour was $54 \mathrm{~min}$.

Acceleration of labour was carried out more in group III and II compared with group I. The mode of delivery is also affected when there is delayed progress of labour; there were increase in number of instrumental deliveries and LSCS as the progress of labour was delayed. The results are comparable to the studies by Impey et al. ${ }^{4}$ (2000) and Javed et al. ${ }^{5}$ (2002). This significantly increased caesarean section rate indicates that the labours are less efficient one the labour curve cross the action line indicating that once the action line is reached the cause of delay should be assessed critically and the measures to terminate the labour should be taken immediately.

For those women who crossed the alert line but not the action line the need for neonatal resuscitation was about three times higher than who delivered before the alert line i.e., in group I, and it was Six times higher in group III. These results suggest that alert line can be considered as an indicator of risk of respiratory distress of new-born.

\section{CONCLUSIONS}

With the help of partograph, the time of delivery could be estimated and if the progress was slow, an appropriate interference at the right time could be instituted before the labour became dangerously protracted. The 'Alert' line on the partograph separates efficient labour from inefficient labour and it detects the earliest possible situation. The 'action' line on the partograph identifies at risk group of women requiring acceleration of labour, intensive monitoring and instrumental deliveries. Oxytocin augmentation at alert line and action line could be useful in decreasing caesarean section rate. However this needs to be confirmed on a large sample study. Use of partograph helps in reducing the incidence of prolonged labour. The neonatal morbidity increases as the 
labour curve moves to the right of the alert line and it is significantly increased as the labour curve crosses the action line. Thus the alert line on the partograph indicates a high risk for the fetus to develop respiratory distress. Use of partograph reduces the incidence of fresh still birth and perinatal mortality.

Funding: No funding sources

Conflict of interest: None declared

Ethical approval: The study was approved by the institutional ethics committee

\section{REFERENCES}

1. Lavender T, Hart A, Smyth RM. Effect of partogram use on outcomes for women in spontaneous labour at term. Cochrane Database Syst Rev. 2008;8(4):CD005461.
2. Daftary SN, Mhatre PN. Cervicograph in the management of labour in primigravidae. J Obstet Gynecol. 1997;27:687-91.

3. Zang J, Troendle JF, Yancey MK. Reassesing the labour curves in nulliparous women. MosbyYearbook Inc. 2002;187(4):824-8.

4. Impey L, Hobson J, O’Herlihy C. Graphic analysis of actively managed labour: prospective computation of labour progress in 500 consecutive nulliparous women in spontaneous labour at term. Am J Obstet Gyanecol. 2000;183(2):438-43.

5. Javed I, Bhutta S, Shoaib T. Role of partogram in preventing prolonged labour. J Pak Med Asso. 2007;57(8):408-11.

DOI: $10.5455 / 2320-1770 . i j r \operatorname{cog} 20140322$

Cite this article as: Bhuyar S, Deshmukh P. Partographic study of progress of labour in primigravida. Int J Reprod Contracept Obstet Gynecol 2014;3:109-12. 